2014-12

\title{
Web-flange distortional buckling of partially restrained cold-formed steel purlins under uplift loading
}

Yuan, W-B

http://hdl.handle.net/10026.1/10966

10.1016/j.jimecsci.2014.10.011

International Journal of Mechanical Sciences

Elsevier BV

All content in PEARL is protected by copyright law. Author manuscripts are made available in accordance with publisher policies. Please cite only the published version using the details provided on the item record or document. In the absence of an open licence (e.g. Creative Commons), permissions for further reuse of content should be sought from the publisher or author. 
The paper has been published on:

International Journal of Mechanical Sciences 89: 476-481, Dec 2014.

\title{
Web-flange distortional buckling of partially restrained cold-formed steel purlins under uplift loading
}

Wei-bin Yuan ${ }^{\mathrm{a}}$, Shanshan Cheng ${ }^{\mathrm{b} *}$, Long-yuan $\mathrm{Li}^{\mathrm{b}}$, Boksun Kim ${ }^{\mathrm{b}}$

a) College of Civil Engineering and Architecture, Zhejiang University of Technology, Hangzhou, China

b) School of Marine Science and Engineering, University of Plymouth, Plymouth, UK

*) corresponding author

\begin{abstract}
It is well-known that cold-formed steel (CFS) members of open section can buckle locally, distortionally and/or lateral-torsionally. Since they are usually used as the secondary structural members in buildings to support roof and side cladding or sheeting, CFS beams are mostly treated as the restrained beams either fully or partially in its lateral and/or rotational directions. For a thin-walled channel- or zed-section beam subjected to uplift loading, if its upper flange is fully restrained in its lateral and rotational directions, the beam will not buckle lateral-torsionally, but may have a web-flange distortional buckling. In literature there is limited information on the web-flange distortional buckling and currently the critical stress for the web-flange distortional buckling is calculated mainly by using numerical methods. In this paper an analytical model is presented to describe the web-flange distortional buckling behaviour of the partially restrained CFS beams when subjected to uplift loading. Formula used to calculate the critical stress of web-flange distortional buckling is derived. Comparisons of the predicted critical stresses with those obtained using finite strip and finite element methods are provided to demonstrate the appropriateness of the model proposed.
\end{abstract}

Keywords: Cold-formed steel, purlin, uplift loading, web-flange distortional buckling.

\section{Introduction}

Thin-walled, cold-formed steel (CFS) sections are mostly used as the intermediate members between the main structural frame and the corrugated roof or wall sheeting in which the upper flange of the section is connected to the sheeting by self-drilling or selftapping screw fasteners, while the lower flange remains free. The most common sections are the channel, zed and sigma shapes, which may be plain or have lips. The lips are small additional elements provided to a section to improve its efficiency under compressive loads. The main features of the CFS section beams are the thin-thickness, open cross-section and large ratio between the two second moments of the cross-section area. These make the section susceptible to local, distortional and lateral-torsional buckling [1].

The local buckling is characterized by the ripples of relatively short half-wavelength of the order of magnitude of individual plate elements in the section and the buckling 
displacements only perpendicular to plane elements while the fold lines remain straight. The critical stress of the local buckling can be calculated using the formula of buckling of plates [1,2]. The distortional buckling occurs only in the structural members of open cross sections. Distortional buckling involves both translation and rotation at the sectional fold lines of a member leading to a distortion of the cross section. The half-wavelength of the distortional buckling mode is typically several times larger than the largest characteristic dimension of the cross-section. Unlike the local buckling in which the critical stress is dependent only on the ratio of the width to thickness of the plate element, the distortional buckling is much more complicated and its critical stress is dependent on the dimensions of not only the buckled flange and lip but also other parts of the section [2-5].

In contrast to the local and distortional buckling, the lateral-torsional buckling generally occurs when a beam which is bent about its major axis develops a tendency to twist and/or displace laterally. Since roof purlins and sheeting rails, in most cases, are restrained against lateral movement by roof or wall cladding, such restraints reduce the potentiality of the lateral buckling of the whole section, but do not necessarily eliminate the problem completely [6]. For example, roof purlins are generally restrained against lateral displacement by the cladding, but under wind uplift which induces compression in the unrestrained flange, lateral-torsional buckling is still a common cause of failure [7]. This occurs due to the flexibility of the restraining cladding and to the distortional flexibility of the section itself which permits lateral movement to occur in the compression flange even if the other flange is restrained. However, there is a case where the lateral-torsional buckling may be prevented, which is that the cladding can also provide a rotational restraint to the purlin. In this case the rotational restraint turns the lateral-torsional buckling mode to a web-flange distortional mode. Note that the webflange distortional buckling is different from the flange-lip distortional buckling. The former is characterized by the translation and rotation of a system consisting of the compression flange and lip plus part of the web, whereas the latter is characterized by the rotation of the compression flange and lip system about the lower flange-web junction. In addition, the wavelength of the web-flange distortional buckling mode is much longer than that of the flange-lip distortional mode. In this paper, investigation will be focused on the web-flange distortional buckling, particularly on the calculation of the critical stress of the web-flange distortional buckling of zed-section purlins with different restraints applied at the upper flange-web junction when subjected to a pure bending about its major axis.

Web-flange distortional buckling of CFS sections has been discussed by several researchers [7-9] by using numerical methods. Hancock defined the web-flange distortional buckling as the lateral-distortional buckling in order to distinguish it from the flange-lip distortional buckling [7]. Early attempt was made to apply the analytical model proposed for the flange-lip distortional buckling to the web-flange distortional buckling but without success [10]. An analytical model was also developed by Svensson [11] and Sokol [12] in which the web-flange distortional buckling was modeled by using an elastically supported column subjected to an axial compression force. The cross section of the column was assumed to consist of the compression flange and lip plus part of the 
web. However, the model was not properly validated.

In this paper an analytical model is presented to describe the web-flange distortional buckling behaviour of partially restrained CFS section beams when subjected to uplift pure bending. Formula used to calculate the critical stress of the web-flange distortional buckling is derived. Comparisons of the predicted critical stresses with those obtained using finite strip and finite element methods are provided to demonstrate the appropriateness of the model proposed.

\section{Web-flange distortional buckling model}

Web-flange distortional buckling occurs in a purlin when its lateral-torsional buckling is partially or fully prevented. Figure 1 shows the typical buckling curves of a zed-section purlin with different restraints applied at the upper flange-web junction when subjected to a pure bending about its major axis. The results were obtained using the finite strip method. It is evident from the figure that the rotational restraint has significant influence on the lateral-torsional buckling of the purlin. When the rotational restraint is strong enough, it can turn the lateral-torsional buckling mode to a web-flange distortional mode.

Consider a zed-section purlin-sheeting system shown in Figure 2a. The load on the sheeting is transferred to the purlin through the self-drilling screws and/or the contact between the sheeting and upper flange. The sheeting provides lateral restraints to the purlin in both the translational and rotational directions. The translational restraint is due to the membrane stiffness of the sheeting, whereas the rotational restraint is provided because of a resisting couple produced by the contact stresses. For most types of sheeting, the translational restraint is much strong and therefore the lateral displacement at the fixing point may be assumed to be fully restrained. The rotational restraint, however, is dependent on several factors. These include the dimensions of sheeting and purlin, number, type and positions of the screws. If the stiffness of the rotational restraint provided by the sheeting is known, then the purlin-sheeting system may be idealized as a purlin with lateral displacement fully restrained and rotation partially restrained at the flange-web junction $[13,14]$, as shown in Figure 2 b.

When the purlin has lateral-torsional buckling and/or web-flange distortional buckling due to uplift loading, the restrained flange and lip system, which is in tension, rotates about its web-flange junction and the free flange and lip system, which is in compression, not only moves laterally but also rotates about its web-flange junction (see Figure 2c). The main difference of the model presented in Figure 2c from that proposed by Svensson [11] and Sokol [12] is that the web and the free flange and lip system can buckle in a combined torsional and flexural buckling mode, whereas in Svensson and Sokol model the system consisting of free flange and lip plus part of the web can buckle only in a flexural mode about the axis parallel to web line [15]. To determine the critical load which can generate such buckling displacements shown in Figure 2c, the change of the total potential energy of the system due to the buckling displacements is to be examined. For simplicity of the presentation, the zed section is split into three components, the 
restrained flange and lip system, the free flange and lip system, and the web. It is assumed that during the lateral-torsional buckling and/or web-flange distortional buckling both the restrained and free flange and lip systems behave like a beam and the web behaves like a plate. According to the displacements defined in Figure $2 \mathrm{c}$, the translation displacements of the restrained and free flange and lip systems can be expressed as follows,

For the free flange and lip system

$$
\begin{aligned}
& v_{s 1}=-b \phi_{1} \\
& w_{s 1}=w_{1}
\end{aligned}
$$

For the restrained flange and lip system

$$
\begin{aligned}
& v_{s 2}=-b \phi_{2} \\
& w_{s 2}=0
\end{aligned}
$$

where $v_{\mathrm{s} 1}$ and $w_{\mathrm{s} 1}$ are the translation displacements of the free flange and lip, $v_{\mathrm{s} 2}$ and $w_{\mathrm{s} 2}$ are the translation displacements of the restrained flange and lip, $b$ is the flange width, $\phi_{1}$ and $\phi_{2}$ are the angles of the rotation of the free and restrained flange and lip systems, respectively. Note that all translation displacements are defined in their local coordinate systems as shown in Figure 2d, where the origin is the centroid for the free/restrained flange and lip systems.

The lateral displacement of the web can be expressed as follows,

$$
w_{3}=-N_{1}(y) w_{1}+N_{2}(y) \phi_{1}+N_{3}(y) \phi_{2}
$$

where $N_{l}(y), N_{2}(y)$ and $N_{3}(y)$ are the interpolation functions defined as follows,

$$
\begin{aligned}
& N_{1}(y)=1-3\left(\frac{y}{h}\right)^{2}+2\left(\frac{y}{h}\right)^{3} \\
& N_{2}(y)=h\left[\frac{y}{h}-2\left(\frac{y}{h}\right)^{2}+\left(\frac{y}{h}\right)^{3}\right] \\
& N_{3}(y)=-h\left[\left(\frac{y}{h}\right)^{2}-\left(\frac{y}{h}\right)^{3}\right]
\end{aligned}
$$

where $h$ is the web depth and $y$ is the local coordinate defined for the web shown in Figure $2 \mathrm{~d}$. The strain energy in each component due to the buckling displacements can be calculated as follows,

$$
\begin{aligned}
U_{1}= & \frac{1}{2} \int_{o}^{l}\left[E I_{y_{1}}\left(\frac{d^{2} w_{s 1}}{d x^{2}}\right)^{2}+2 E I_{y z 1} \frac{d^{2} v_{s 1}}{d x^{2}} \frac{d^{2} w_{s 1}}{d x^{2}}+E I_{z 1}\left(\frac{d^{2} v_{s 1}}{d x^{2}}\right)^{2}\right] d x \\
& +\frac{1}{2} \int_{o}^{l} G J_{1}\left(\frac{d \phi_{1}}{d x}\right)^{2} d x+\frac{1}{2} \int_{o}^{l} E A_{1}\left(b-e_{z 1}\right)^{2}\left(\frac{d^{2} w_{1}}{d x^{2}}\right)^{2} d x \\
U_{2}= & \frac{1}{2} \int_{o}^{l}\left[E I_{z 2}\left(\frac{d^{2} v_{s 2}}{d x^{2}}\right)^{2}+G J_{2}\left(\frac{d \phi_{2}}{d x}\right)^{2}+k_{\phi} \phi_{2}^{2}\right] d x
\end{aligned}
$$


$U_{3}=\frac{D}{2} \int_{o}^{l} \int_{o}^{h}\left[\left(\frac{\partial^{2} w_{3}}{\partial x^{2}}+\frac{\partial^{2} w_{3}}{\partial y^{2}}\right)^{2}+2(1-v)\left(\left(\frac{\partial^{2} w_{3}}{\partial x \partial y}\right)^{2}-\frac{\partial^{2} w_{3}}{\partial x^{2}} \frac{\partial^{2} w_{3}}{\partial y^{2}}\right)\right] d x d y$

where $U_{1}$ and $U_{2}$ are the strain energies of the free and restrained flange and lip systems, $U_{3}$ is the strain energy of the web, $E$ is the Young's modulus, $G$ is the shear modulus, $v$ is the Poisson's ratio, $t$ is the thickness, $l$ is the beam length, $D=\frac{E t^{3}}{12\left(1-v^{2}\right)}$ is the flexural rigidity of the web plate, $k_{\phi}$ is the rotational spring constant, $I_{y 1}$ is the moment of inertia of the free flange and lip system about $y$-axis, $I_{z 1}=I_{z 2}$ is the moment of inertia of the free/restrained flange and lip system about $z$-axis, $I_{y z 1}$ is the product moment of crosssection area of the free flange and lip system, $J_{l}=J_{2}$ is the torsional constant of the free/restrained flange and lip system, and $e_{z 1}$ is the $z$-coordinate of the shear centre of the free flange and lip system in the local coordinate system. All properties are defined in the local coordinate systems shown in Figure $2 \mathrm{~d}$.

For the case of pure bending, the free flange and lip are in compression and the restrained flange and lip are in tension. Ignoring the stress variation in lips, the potential energy of the pre-buckling axial stresses in the free and restrained flange and lip systems can be expressed as follows [16,17],

$$
\begin{aligned}
& W_{1}=\frac{\sigma_{c r} A_{1}}{2} \int_{o}^{l}\left[\left(\frac{d v_{s 1}}{d x}+e_{z 1} \frac{d \phi_{1}}{d x}\right)^{2}+\left(\frac{d w_{s 1}}{d x}-e_{y 1} \frac{d \phi_{1}}{d x}\right)^{2}+\left(r_{c 1} \frac{d \phi_{1}}{d x}\right)^{2}\right] d x \\
& W_{2}=-\frac{\sigma_{c r} A_{2}}{2} \int_{o}^{l}\left[\left(\frac{d v_{s 2}}{d x}+e_{z 2} \frac{d \phi_{2}}{d x}\right)^{2}+\left(\frac{d w_{s 2}}{d x}-e_{y 2} \frac{d \phi_{2}}{d x}\right)^{2}+\left(r_{c 2} \frac{d \phi_{2}}{d x}\right)^{2}\right] d x
\end{aligned}
$$

where $W_{1}$ and $W_{2}$ are the potential energies of the pre-buckling stresses in the free and restrained flange and lip systems, $\sigma_{c r}$ is the critical stress, $e_{y 2}=e_{y 1}$ and $e_{z 2}=e_{z 1}$ are the $y$ and $z$-coordinates of the shear centre of the restrained/free flange and lip system in the local coordinate system, $A_{1}=A_{2}$ is the area of the free/restrained flange and lip system, and $r_{c 1}=r_{c 2}$ is the polar radius of gyration of the free/restrained flange and lip system. The potential energy of the pre-buckling axial stress in the web can be calculated as follows,

$$
W_{3}=\frac{t}{2} \int_{o}^{l} \int_{o}^{h} \sigma_{c r}\left(1-\frac{2 y}{h}\right)\left(\frac{\partial w_{3}}{\partial x}\right)^{2} d x d y
$$

where $W_{3}$ is the potential energy of the pre-buckling stress in the web. Assume that the displacements of the beam when it buckles can be described as follows,

$$
\begin{aligned}
& w_{1}(x)=C_{1} \sin \frac{k \pi x}{l} \\
& \phi_{1}(x)=C_{2} \sin \frac{k \pi x}{l} \\
& \phi_{2}(x)=C_{3} \sin \frac{k \pi x}{l}
\end{aligned}
$$


where $C_{1}, C_{2}$ and $C_{3}$ are the constants to be determined, and $k$ is the number of halfwaves. The condition when the buckling occurs is the total potential of the system has a stationary condition with respect to the constants $C_{1}, C_{2}$ and $C_{3}$, that is,

$$
\begin{aligned}
& \frac{\partial \Pi}{\partial C_{1}}=\frac{\partial}{\partial C_{1}}\left(U_{1}+U_{2}+U_{3}-W_{1}-W_{2}-W_{3}\right)=0 \\
& \frac{\partial \Pi}{\partial C_{2}}=\frac{\partial}{\partial C_{2}}\left(U_{1}+U_{2}+U_{3}-W_{1}-W_{2}-W_{3}\right)=0 \\
& \frac{\partial \Pi}{\partial C_{3}}=\frac{\partial}{\partial C_{3}}\left(U_{1}+U_{2}+U_{3}-W_{1}-W_{2}-W_{3}\right)=0
\end{aligned}
$$

Substituting Eqs. (15)-(17) into (1)-(5), then into (9)-(14), it yields

$$
\left[\begin{array}{lll}
A_{11} & A_{12} & A_{13} \\
A_{21} & A_{22} & A_{23} \\
A_{31} & A_{32} & A_{33}
\end{array}\right]\left\{\begin{array}{l}
C_{1} \\
C_{2} \\
C_{3}
\end{array}\right\}=\sigma_{c r}\left[\begin{array}{lll}
B_{11} & B_{12} & B_{13} \\
B_{21} & B_{22} & B_{23} \\
B_{31} & B_{32} & B_{33}
\end{array}\right]\left\{\begin{array}{l}
C_{1} \\
C_{2} \\
C_{3}
\end{array}\right\}
$$

in which

$$
\begin{aligned}
& A_{11}=E I_{y 1}\left(\frac{k \pi}{l}\right)^{2}+E A_{1}\left(b-e_{z 1}\right)^{2}\left(\frac{k \pi}{l}\right)^{2}+\frac{13 h D}{35}\left(\frac{k \pi}{l}\right)^{2}+\frac{12 D}{5 h}+\frac{12 D}{h^{3}}\left(\frac{l}{k \pi}\right)^{2} \\
& A_{12}=A_{21}=-b E I_{y z 1}\left(\frac{k \pi}{l}\right)^{2}-\frac{11 h^{2} D}{210}\left(\frac{k \pi}{l}\right)^{2}-\frac{6 D}{5}-\frac{6 D}{h^{2}}\left(\frac{l}{k \pi}\right)^{2}+D(1-v) \\
& A_{13}=A_{31}=\frac{13 h^{2} D}{420}\left(\frac{k \pi}{l}\right)^{2}-\frac{D}{5}-\frac{6 D}{h^{2}}\left(\frac{l}{k \pi}\right)^{2} \\
& A_{22}=b^{2} E I_{z 1}\left(\frac{k \pi}{l}\right)^{2}+G J_{1}+\frac{h^{3} D}{105}\left(\frac{k \pi}{l}\right)^{2}+\frac{4 h D}{15}+\frac{4 D}{h}\left(\frac{l}{k \pi}\right)^{2} \\
& A_{23}=A_{32}=-\frac{h^{3} D}{140}\left(\frac{k \pi}{l}\right)^{2}-\frac{h D}{15}+\frac{2 D}{h}\left(\frac{l}{k \pi}\right)^{2} \\
& A_{33}=b^{2} E I_{z 2}\left(\frac{k \pi}{l}\right)^{2}+G J_{2}+k_{\phi}\left(\frac{l}{k \pi}\right)^{2}+\frac{h^{3} D}{105}\left(\frac{k \pi}{l}\right)^{2}+\frac{4 h D}{15}+\frac{4 D}{h}\left(\frac{l}{k \pi}\right)^{2} \\
& B_{11}=A_{1}+\frac{h t}{5} \\
& B_{12}=B_{21}=-e_{y 1} A_{1}-\frac{2 h^{2} t}{105} \\
& B_{13}=B_{31}=\frac{h^{2} t}{420} \\
& B_{22}=\left(\left(e_{z 1}-b\right)^{2}+e_{y 1}^{2}+r_{c 1}^{2}\right) A_{1}+\frac{h^{3} t}{420} \\
& B_{23}=B_{32}=0
\end{aligned}
$$




$$
B_{33}=-\left(\left(e_{z 2}-b\right)^{2}+e_{y 2}^{2}+r_{c 2}^{2}\right) A_{2}-\frac{h^{3} t}{420}
$$

Eq. (21) is an eigenvalue equation from which the critical stress $\sigma_{c r}$ can be determined.

\section{Numerical examples}

As numerical examples, three zed-sections are analyzed, representing small, medium and large size sections. The purlins are fully restrained in lateral direction and partially restrained in rotational direction, subjected to pure bending. The corresponding critical stresses calculated from the present model for three different rotational spring constants [18] are presented in Figures 3-5, respectively. To demonstrate the present model, results obtained from the finite strip method $[19,20]$ are also superimposed in the figures. It can be seen from the figures that the critical stresses predicted from the present model are in good agreement with those obtained from the finite strip method. It is only for the beams shorter than $3.5 \mathrm{~m}$ for the small size section $(h=150 \mathrm{~mm}), 4.5 \mathrm{~m}$ for the medium size section $(h=250 \mathrm{~mm})$, and $5.0 \mathrm{~m}$ for the large size section $(h=350 \mathrm{~mm})$ where the predicted critical stresses are slightly higher than those obtained from the finite strip method. This is due to the deformation assumption for the web plate using a cubic interpolation function, which has limited degrees of freedom. Nevertheless, the differences between them are not significant. For example, the relative error of the critical stress between the present and finite strip methods is less than $10 \%$ for a $2 \mathrm{~m}$ long beam of $h=150 \mathrm{~mm}$, a $3 \mathrm{~m}$ long beam of $h=250 \mathrm{~mm}$, and a $4 \mathrm{~m}$ long beam of $h=350$ $\mathrm{mm}$. This demonstrates that the combination of the beam model for the flange and lip systems and the plate model for the web employed in the present model is appropriate and able to represent the web-flange distortional buckling behaviour of partially restrained purlins. It can also be seen from the figures that, for beams with no rotational restraint the critical stress decreases constantly with the beam length; whereas for beams with rotational restraint the critical stress decreases initially but afterwards it increases with a further increased beam length. Whether or not there exists a minimum point in the critical curve is dependent on the value of the rotational spring constant. To eliminate the possibility of lateral-torsional buckling the rotational spring constant has to reach a certain value, in which case the lateral-torsional buckling is replaced completely by the web-flange distortional buckling. Similar to the local and distortional buckling of most CFS members, the web-flange distortional buckling has a minimum critical stress with a certain wavelength. Therefore, for partially restrained purlins, if the rotational restraint is sufficient large, the buckling design of the purlins can be done based on the minimum critical stresses of local, distortional and web-flange distortional buckling, all of which can be characterized by their wavelengths that are independent of the beam length. Also, it can be observed from Figures 3-5 that, for the same section the critical stress difference between two rotational spring constants increases with the beam length. This indicates that the rotational spring has more influence on the critical stress of longer beams. Note that the normal span length of a purlin is between 3 and $6 \mathrm{~m}$. Purlins with span longer than $6 \mathrm{~m}$ often have anti-sag bars that provide additional lateral restrains, which will 
influence the web-flange distortional buckling behavior of the purlin, which is not covered by the present study.

To further validate the present analytical solution, linear buckling analysis using the finite element method has also been carried out by using the commercial software ANSYS. Four-node rectangular shell element with elastic material properties was used. Because of symmetry only a half of the purlin length was modelled. All nodes on the symmetric section were assumed to have zero axial displacement, zero rotations about lateral and transverse axes. All nodes on the end section were assumed to have zero displacements in lateral and transverse axes. The pure bending moment about the major axis was added on the end section by using linearly distributed axial stresses. All nodes on the junction line between web and upper flange were assumed to have zero lateral displacement. The comparison of the critical stresses of web-flange buckling between the finite element analysis and the present solution is shown in Figure 6. Figure 7 shows a typical mode of the web-flange buckling of a purlin analyzed. Again, a good agreement between the finite element analysis and the present analytical solution is demonstrated.

Eq. (21) provides a general case in which the buckling mode could be the combination of the lateral-torsional buckling and web-distortional buckling modes. A special case of it is when the web plate has no bending deformation along the web line. In this case the rotations of two flanges and the translation displacement of bottom flange are longer independent, and instead, they have the relationships of $w_{i}=h \phi_{1}=h \phi_{2}$. Thus, the critical stress can be directly expressed as follows,

$\sigma_{c r}=\frac{h^{2} A_{11}+A_{22}+A_{33}+2 h\left(A_{12}+A_{13}\right)+2 A_{23}}{h^{2} B_{11}+B_{22}+B_{33}+2 h\left(B_{12}+B_{13}\right)+2 B_{23}}$

\section{Conclusions}

This paper has presented an analytical study on the web-flange distortional buckling of partially restrained zed-section purlins subjected to pure bending. The formula of calculating critical stress of web-flange distortional buckling has been derived using energy method. The critical stresses predicted using the present model have been validated using both the finite strip and finite element methods for purlins with small, medium and large size sections. From the obtained results the following conclusions can be drawn:

- Rotational restraint applied at the tension flange has a significant influence on the lateral-torsional buckling of purlins. It can turn the lateral-torsional buckling into a web-flange distortional buckling if the rotational spring constant reaches a certain value.

- Unlike the lateral-torsional buckling for which the critical stress decreases continuously with the beam length, the web-flange distortional buckling has a critical stress that decreases initially with the beam length, but increases afterwards with further increased beam length. 
- The minimum critical stress of web-flange distortional buckling occurs at a particular wavelength, which decreases with the increase of rotational spring constant, which is usually less than the beam length.

- The critical stress of lateral-torsional buckling or web-flange distortional buckling increases with the rotational spring constant. However, for an identical rotational spring constant the longer the beam, the more the increase of the critical stress.

Acknowledgement - The second author wishes to acknowledge the financial support received from the Chinese Scholarship Council for her PhD study being carried out at Plymouth University.

\section{References}

[1] Li LY and Chu XT. Cold-formed Steel Sections (Chapter 11]). In: Martin LH and Purkiss JA: Structural Design of Steelwork. Oxford, Elsevier 2007; p.411-457.

[2] EN 1993-1-3. Eurocode 3 - Design of Steel Structures - Part 1-3: General rules Supplementary rules for cold-formed members and sheeting. BSI, 2006.

[3] Hancock GJ. Design for distortional buckling of flexural members. Thin-Walled Structures 1997; 27(1): 3-12.

[4] Li LY and Chen JK. An analytical model for analyzing distortional buckling of coldformed steel sections. Thin-Walled Structures 2008; 46(12): 1430-1436.

[5] Li LY. Analyses of distortional buckling of cold-formed sigma purlins using EN 1993-1-3. Journal of Constructional Steel Research 2009; 65(12): 2099-2102.

[6] Li LY. Lateral-torsion buckling of cold-formed zed-purlins partial-laterally restrained by metal sheeting. Thin-Walled Structures 2004; 42(7): 995-1011.

[7] Hancock GJ. Cold-formed steel structures. Journal of Constructional Steel Research 2003; 59(4): 473-87.

[8] Chu XT, Ye ZM, Li LY and Kettle R. Local and distortional buckling of cold-formed zed-section beams under uniformly distributed loads. International Journal of Mechanical Sciences 2006; 48(4): 378-388.

[9] Ye ZM, Kettle R, Li LY and Schafer BW. Buckling behaviour of cold-formed zedpurlins partially restrained by steel sheeting. Thin-walled Structures 2002; 40(10): 853-864.

[10] Roger CA and Schuster RM. Flange/web distortional buckling of cold-formed steel sections in bending. Thin-Walled Structures 1997; 27(1): 13-29.

[11] Svensson SE. Lateal buckling of beams analysed as elastically supported columns subject to a varying axial force. Journal of Constructional Steel Research 1985; 5(3): 179-193.

[12] Sokol L. Stability of cold formed purlins braced by steel sheeting. Thin-Walled Structures 1996; 25(4): 247-268.

[13] Ren C, Li LY and Yang J. Bending analysis of partially restrained channel- section purlins subjected to up-lift loadings. Journal of Constructional Steel Research 2012; 72: $254-260$. 
[14] Li LY, Ren C and Yang J. Theoretical analysis of partially restrained zed-purlin beams subjected to up-lift loads. Journal of Constructional Steel Research 2012; 70: 273-279.

[15] Li LY. Calculation of moment capacity of cold-formed steel members. International Journal of Structural Engineering 2011; 2(2): 101-115.

[16] Chen JK and Li LY. Distortional buckling of cold-formed steel sections subjected to uniformly distributed transverse loading. International Journal of Structural Stability and Dynamics 2010; 10(5): 1017-1030.

[17] Alwis WA and Wang CM. Wagner term in flexural-torsional buckling of thin-walled open-profile columns. Engineering Structures 1996; 18(2): 125-132.

[18] Zhao CX, Yang J, Wang FL, Chan AHC. Rotational stiffness of cold-formed steel roof purlin-sheeting connections. Engineering Structures 2014; 59: 284-297.

[19] Schafer BW. Cold-formed Steel Behaviour and Design: Analytical and Numerical Modelling of Elements and Members with Longitudinal Stiffeners. PhD Thesis. Cornell University, 1997.

[20] Schafer BW. Elastic buckling analysis of thin-walled members using the classical finite strip method, CUFSM Version 2.6 Johns Hopkins University, 2003. 


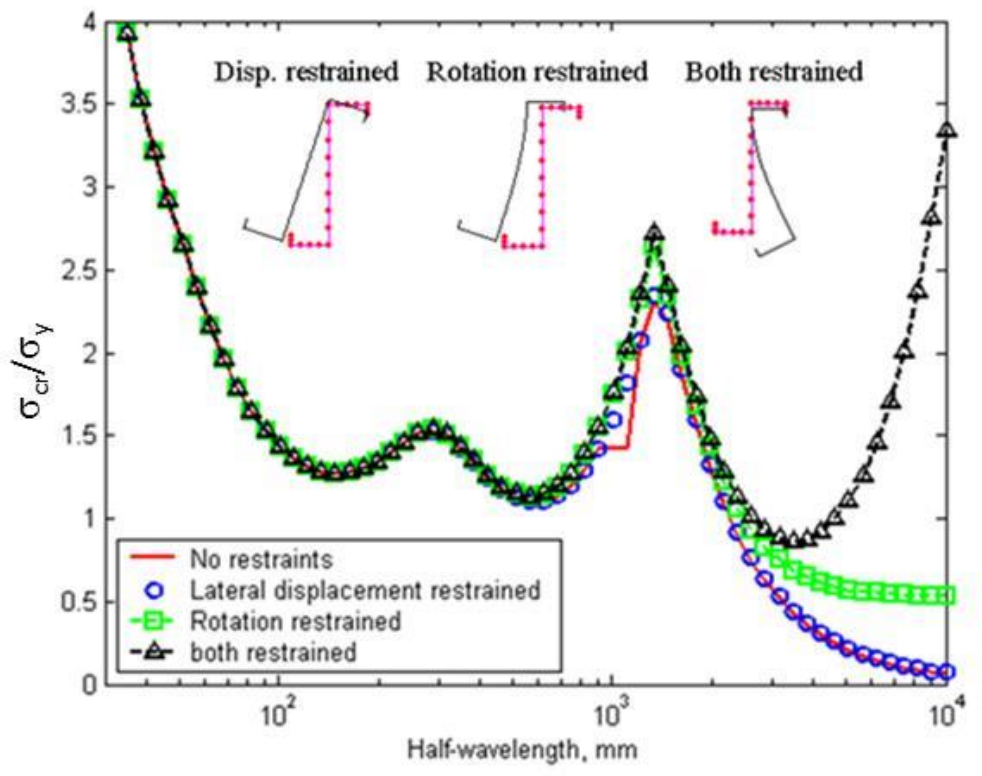

Figure 1. Buckling curves and lateral-torsional buckling/web-flange distortional buckling modes of a zed-section purlin with different restraints applied at the upper flange-web junction (tension zone) when subjected to a pure bending ( $h=270 \mathrm{~mm}, b=70 \mathrm{~mm}, c=$ $\left.20 \mathrm{~mm}, t=2.5 \mathrm{~mm}, \sigma_{y}=390 \mathrm{MPa}\right)$.

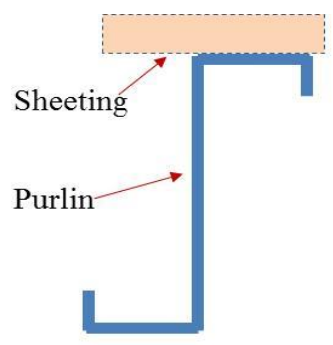

(a)

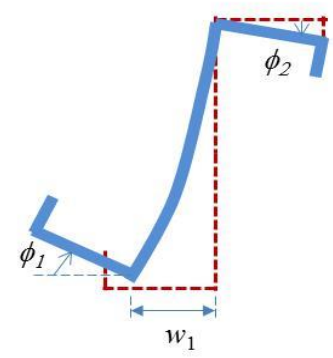

(c)

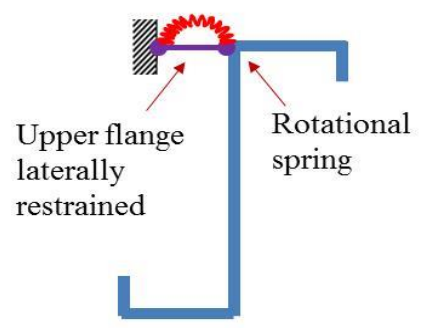

(b)

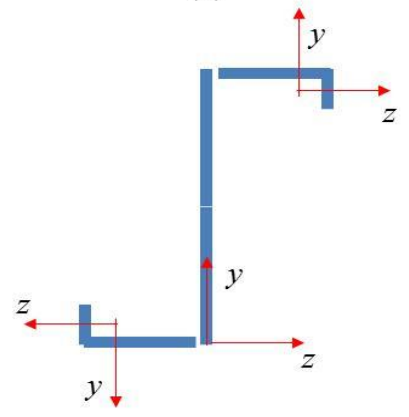

(d)

Figure 2. (a) Purlin-sheeting system. (b) Analysis mode. (c) Displacements representing web-flange distortional buckling. (d) Coordinate systems used in individual components. 


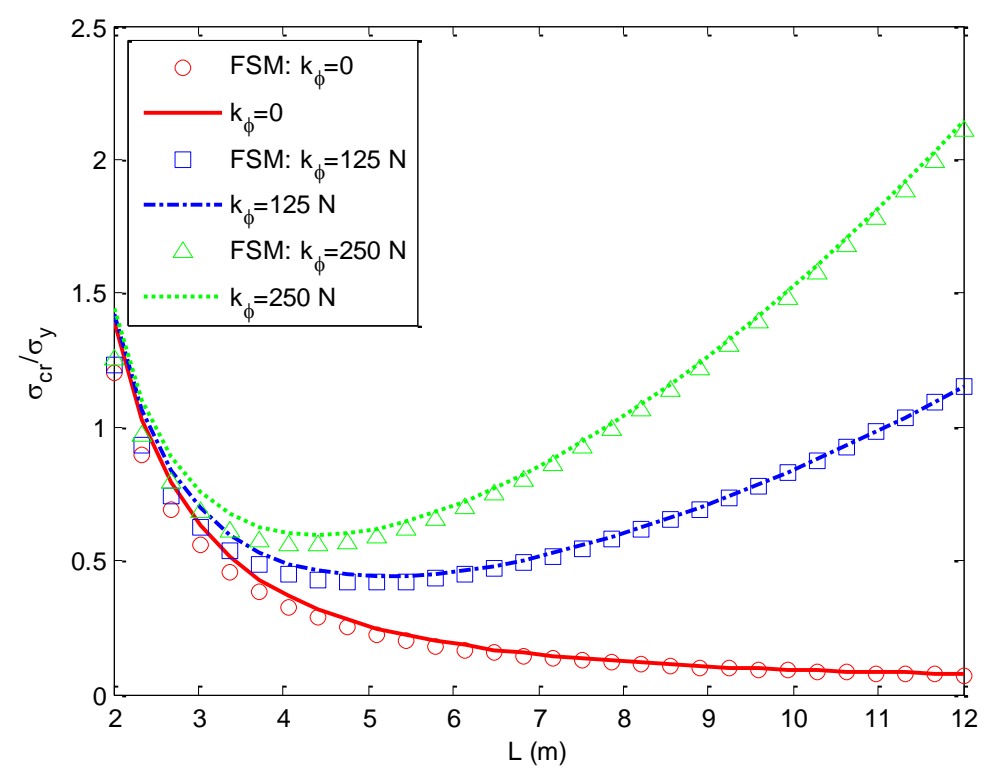

Figure 3. Critical stress of web-flange distortional buckling of a zed-section (a small section: $h=150 \mathrm{~mm}, b=50 \mathrm{~mm}, c=20 \mathrm{~mm}, t=2.0 \mathrm{~mm}, \sigma_{y}=390 \mathrm{MPa}$ ).

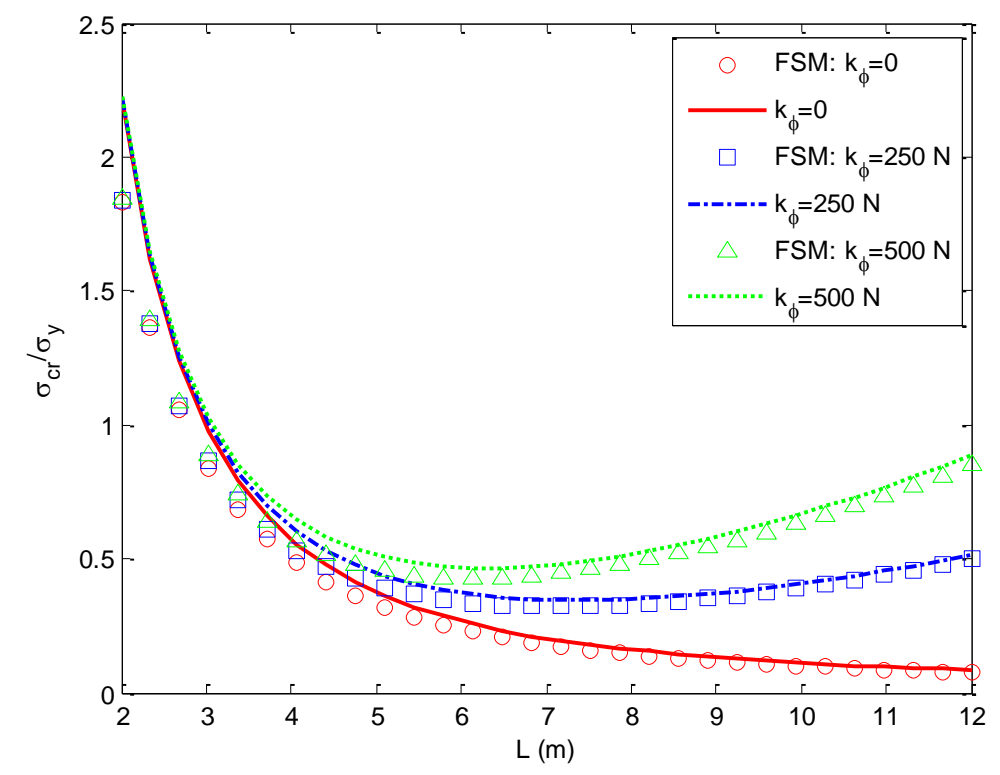

Figure 4. Critical stress of web-flange distortional buckling of a zed-section (a medium section: $h=250 \mathrm{~mm}, b=70 \mathrm{~mm}, c=20 \mathrm{~mm}, t=2.5 \mathrm{~mm}, \sigma_{y}=390 \mathrm{MPa}$ ). 


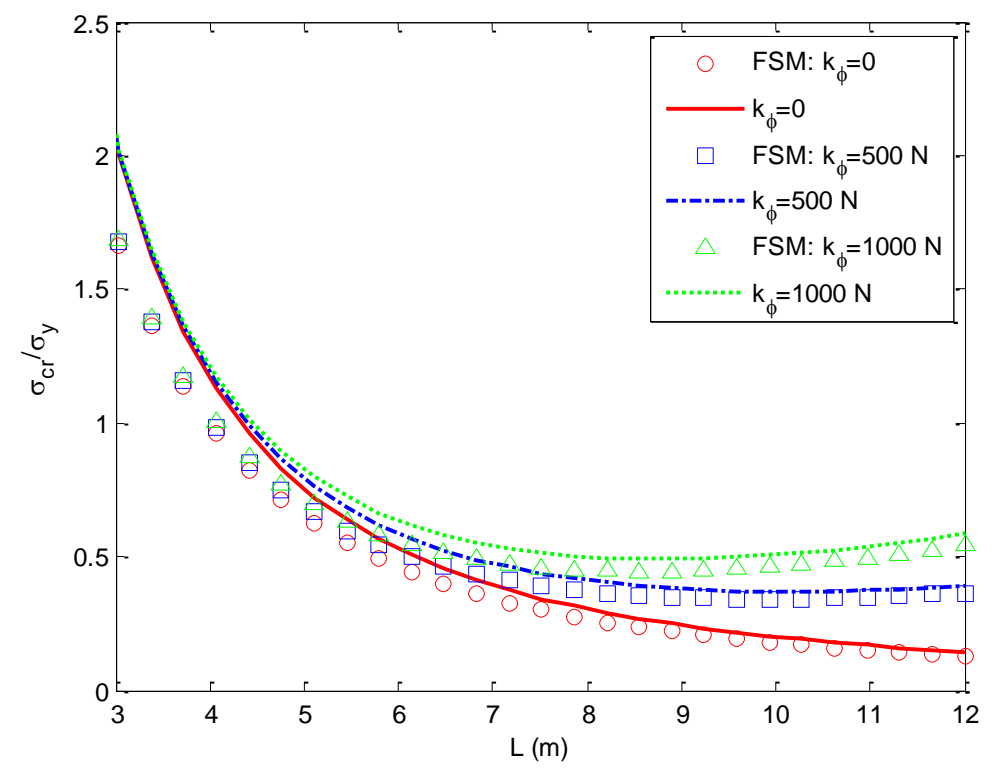

Figure 5. Critical stress of web-flange distortional buckling of a zed-section (a large section: $h=350 \mathrm{~mm}, b=100 \mathrm{~mm}, c=30 \mathrm{~mm}, t=3.0 \mathrm{~mm}, \sigma_{y}=390 \mathrm{MPa}$ ).

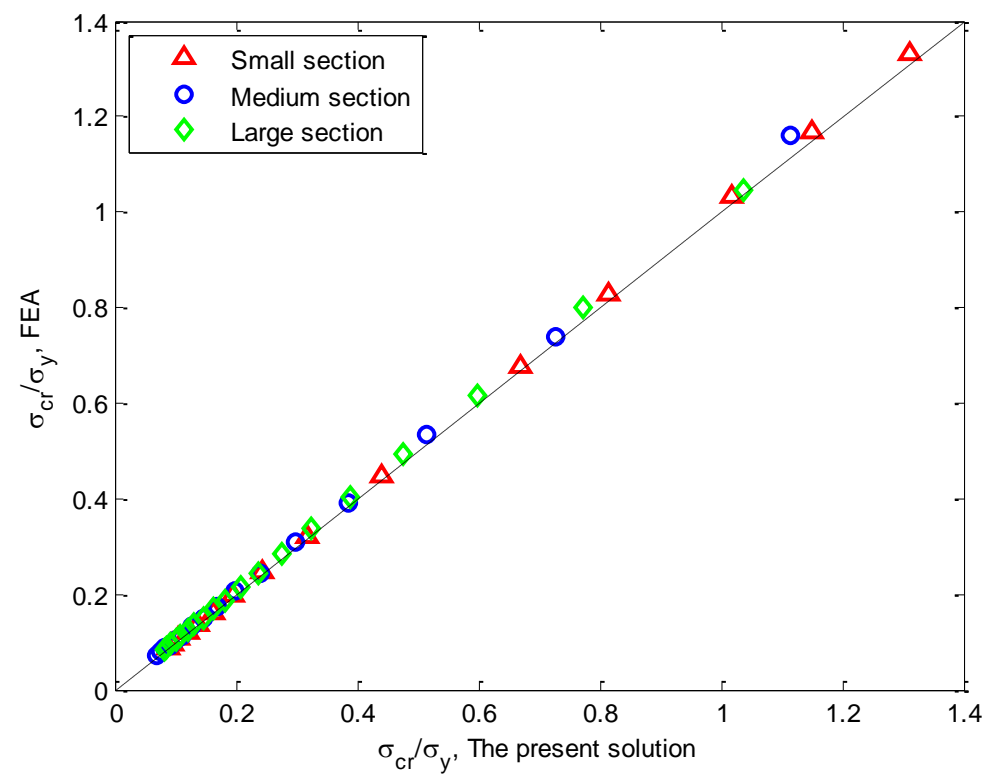

Figure 6. Comparison of critical stresses of web-flange distortional buckling of small, medium and large zed-section purlins between FEA and present analytical solution. 


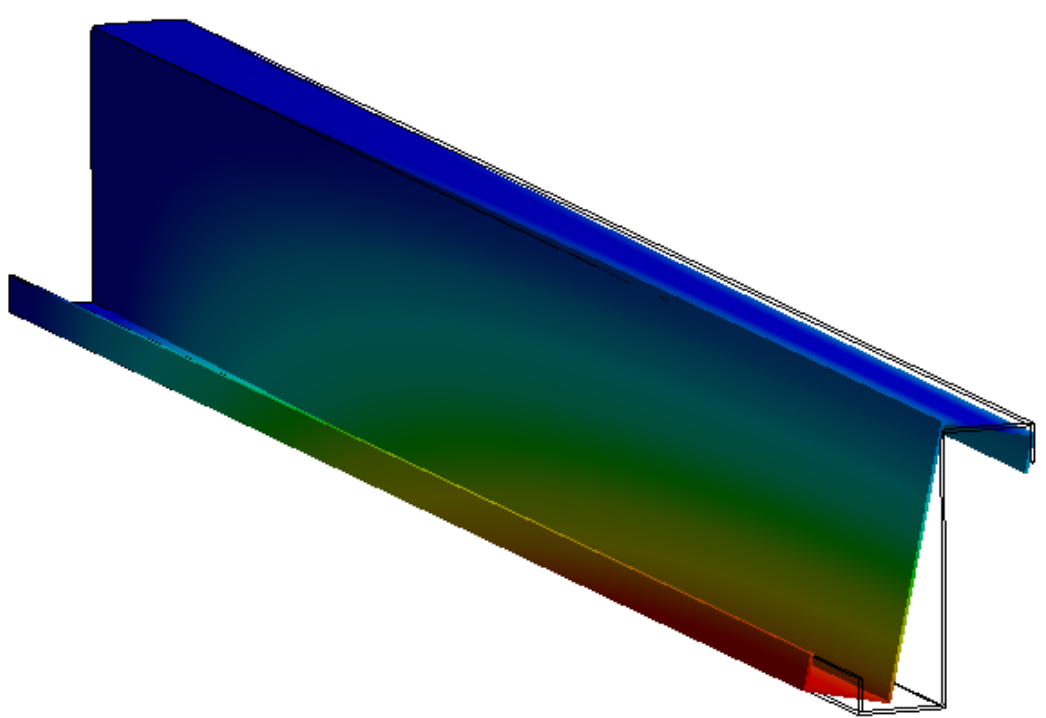

Figure 7. The critical mode of web-flange buckling of the small size section purlin $(h=$ $150 \mathrm{~mm}, b=50 \mathrm{~mm}, c=20 \mathrm{~mm}, t=2.0 \mathrm{~mm}, l=2.5 \mathrm{~m})$. 